\title{
Human Papillomavirus-18 Positive
}

National Cancer Institute

\section{Source}

National Cancer Institute. Human Papillomavirus-18 Positive. NCI Thesaurus. Code C131711.

An indication that human papillomavirus-18 has been detected in a sample. 